\title{
Gold(I)-catalyzed 7-exo-dig Cyclization: A Key Step to Access the Bicyclo[4.2.1]nonane Skeleton of Vibsatin A, a Neu- rotrophic Diterpenoid
}

\author{
Luca Allievi, ${ }^{\dagger}$ Sabrina Dhambri, ${ }^{\dagger}$ Rongyu Sun, Mohamed Selkti, Marie-Isabelle Lannou, ${ }^{*}$ Geoffroy \\ Sorin,* Janick Ardisson* \\ UMR CNRS 8038, Faculté de Pharmacie, Université de Paris, 4 avenue de l'Observatoire, 75270 Paris cedex 06 \\ Supporting Information Placeholder
}

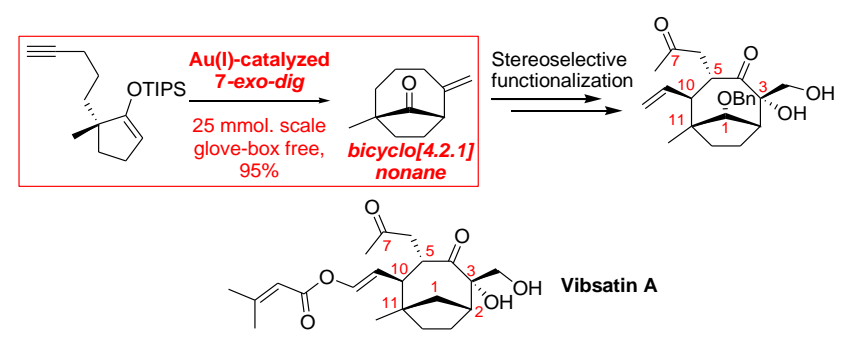

\begin{abstract}
Vibsatin A is a new neurotrophic vibsane-type diterpenoid comprising a bridged bicyclo[4.2.1]nonane skeleton. Inspired by Sawamura's works, the generation of the bicyclic backbone was smoothly achieved through a Conia-ene derived 7-exodig cyclization from an enantiomerically enriched TIPS-based silyl enol ether. The reaction, catalyzed by a sensitive gold(I) complex, was efficiently performed on large scale by glove-box free techniques. Furthermore, the shape of this system was exploited for subsequent installation of all the stereogenic centres.
\end{abstract}

Developing straightforward approaches towards the construction of various complex and polycyclic architectures in three dimensions is essential for the synthesis of biologically active products. In this context, the efficient synthesis of rigid bridged bicyclo[4.2.1]nonane skeletons encountered in significant natural alkaloids and terpenoids such as ajmaline, ${ }^{1}$ isokopsine, ${ }^{2}$ echinopines, ${ }^{3}$ and vibsatins ${ }^{4}$ can afford opportunities to investigate new methodologies and their limits.

Our group cultivated interest for developing an effective chemical route towards the $5 / 7$ bridged core of vibsatin A 1 . This vibsane-type diterpenoid, isolated in 2014 from the Chinese plant Viburnum tinus $c v$. variegatus by Zhao et al, was found to induce significant neurite outgrowth. ${ }^{4,5}$ Moreover, if different synthetic studies were accomplished towards the elaboration of various vibsane natural substances, ${ }^{6}$ no synthesis of this new sub-type was reported to date. Herein, the asymmetric construction of the bicyclo[4.2.1]nonane skeleton of vibsatin A 1 and the stereocontrolled introduction of all the stereogenic centres is reported.

Taking advantage of the bicyclic shape of the molecule, the envisioned strategy is based on the enantioselective installation of a single stereocentre which would induce the stereocontrol of all others. Thus, accessing the bicyclo[4.2.1]nonane skeleton $\mathbf{4}$ of vibsatin A $\mathbf{1}$ in a stereoselective manner appeared of primary interest, although the synthesis of medium size carbocycles like 7-membered rings is renowned to be highly challenging (Scheme 1). In 2010, Sawamura's group developed a bulky semihollow-shaped phosphine which, in association with gold(I), allowed the unprecedented gold catalysed formation of 7-membered rings through a Conia-ene derived 7-exo-dig process, from alkyne-tethered silyl enol ethers. ${ }^{7,8}$ Though this work represented a remarkable advance, it was achieved on a very small scale $(0.1 \mathrm{mmol}$ scale $\approx 20 \mathrm{mg}$ ) and required glovebox techniques, thus restricting its application field.

Hence, it has been foreseen to develop this carbocyclization in order to access bicyclic ketone $\mathbf{4}$, from enantiomerically enriched silyl enol ether 5. Although an adaptation of the procedure was required, this reaction would enable, in a single step, the construction of the desired [5-7]-bicyclic bridged backbone in the right configuration at $\mathrm{C} 2$ and $\mathrm{C} 11$. An asymmetric Michael addition from 2-methylcyclopentanone $\mathbf{6}$ would provide the $(R)$ configuration at $\mathrm{C} 11$ required for the substrate $\mathbf{5}$ of the cycloaddition step. Then, oxidations and deoxygenation of the bicycle 4 would allow the formation of the $\alpha, \beta$ unsaturated ketone 3 . Further 1,4-addition was expected to functionalize the $\mathrm{Si}$-face of the double bond leading to a $10(S)$ configuration. Subsequent C-allylation would position an allyl chain at C5 in a trans-fashion leading to 2 and to the setting of the last stereogenic centre present in vibsatin A. The synthesis 
of vibsatin A 1 would then be completed by a Wacker oxidation at the double bond and a Wittig olefination for the installation of the lateral chain (Scheme 1).

Scheme 1. Synthetic strategy.
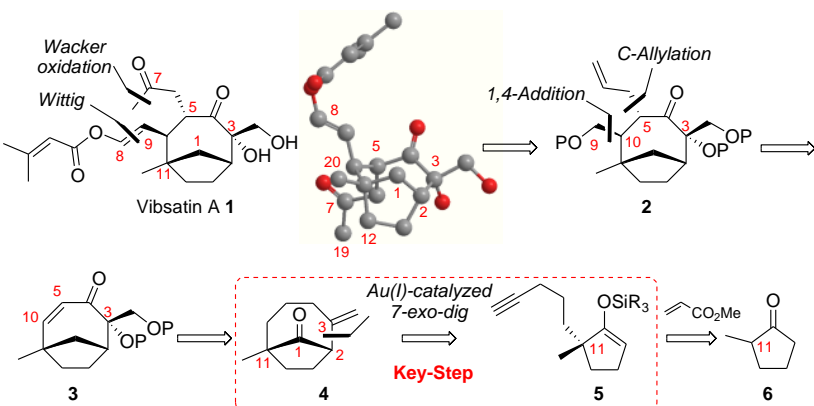

The first goal was the synthesis of the alkyne-tethered silyl enol ether 5 from 2-methylcyclopentanone 6. In order to control the quaternary stereocentre at $\mathrm{C} 11$, we choose to rely on the works of d'Angelo and Desmaële. ${ }^{9}$ The known enantioenriched keto ester $(R)-7$ was easily obtained in $93 \%$ yield and $91 \%$ e.e., by deracemizing Michael addition of the imine derived from 2-methylcyclopentanone $\mathbf{6}$ and $(S)$-1phenylethylamine on methyl acrylate. After protection of the ketone as a dioxolane group and reduction of the ester, ${ }^{10}$ the corresponding alcohol $\mathbf{8}$ was transformed into its tosylate derivative 9. Subsequent displacement of this group by lithium-acetylide followed by acidic treatment provided ketone $\mathbf{1 0}$ in high yield. ${ }^{11}$ This seven step sequence from 2methylcyclopentanone 6 resulted in $50 \%$ overall yield thus delivering 24.6 grams $(0.15 \mathrm{~mol}$.) of ketone 10. At this stage, two different silyl groups were introduced with the formation of the TBS-based silyl enol ether $\mathbf{5 a}$ and the bulkier TIPSderivative $\mathbf{5 b}$, in quantitative yields (Scheme 2).

Scheme 2. Synthesis of acetylenic silyl enol ethers 5a-b.

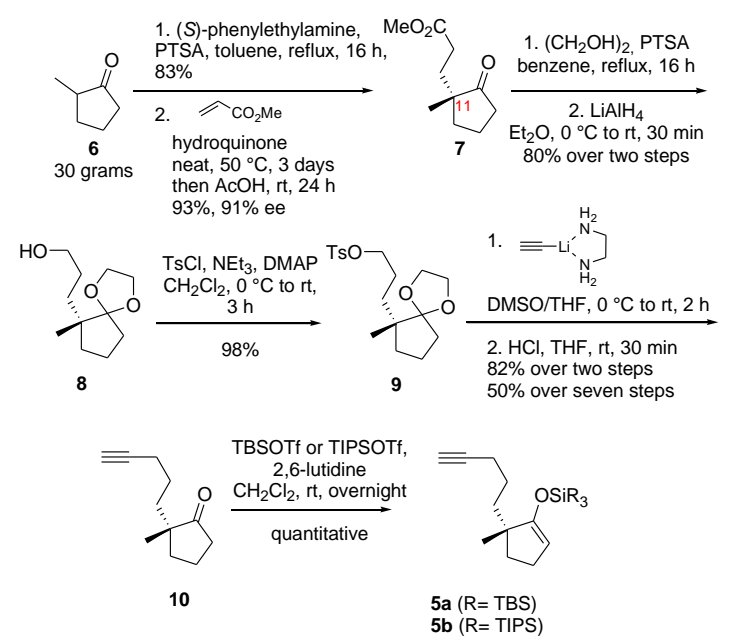

With the substrates 5a-b in hands, the 7-exo-dig cyclization reaction was examined. For practical reasons, an adaptation of Sawamura's procedure ${ }^{8 b}$ to glove-box free conditions for subsequent application on large scale constituted our main objective. Synthesis of the bulky triethynylphosphine $\mathbf{1 1}$ was realized in three steps starting from 30 grams of bromophenol derivative in an overall yield of $53 \%$ (see Supporting Information). The 7-exo-dig cyclization necessitated an important optimization process. In order to run these reactions on a simple vacuum line, tailor-made Schlenk tubes were designed (see Supporting Information). This specific glassware allowed the in situ generation of the active gold catalyst [(11)Au] $\mathrm{NTf}_{2}$ without the need for a glovebox at the crucial ligand exchange step. Our study started by investigating the 7-exo-dig cyclization on $0.3 \mathbf{m m o l}$ of $\mathbf{5 a}$ and $\mathbf{5 b}$; most significant results are combined in Table 1. The first attempt from $\mathbf{5 a}$, at room temperature, in the presence of $5 \mathrm{~mol} \%$ catalyst and one equivalent of $t \mathrm{BuOH}$ in dichloromethane, with a substrate concentration of $0.02 \mathrm{M}$, resulted in total cleavage of the silyl enol ether function, regenerating ketone 10 (100\% conversion, 4/10 8:92, Entry 1). Unlike Sawamura's report, moving toward the TIPSbased silyl enol ether $\mathbf{5} \mathbf{b}$ provided better results. Hence, a first trial, at room temperature, resulted in the total conversion of the substrate into the bicyclic target molecule $\mathbf{4}$ and an isolated yield of $80 \%$ was reached (Entry 2). With this good result in hands, concentration was raised to $0.05 \mathrm{M}$, affording 4 in $92 \%$ yield (Entry 3). Further increase in the reaction concentration $([\mathrm{M}]=0.1 \mathrm{M})$ finally afforded the best result in terms of isolated yield (95\%) (Entry 4). Ultimate application of these optimized conditions to a large scale cyclization reaction allowed the transformation to operate from more than $8 \mathrm{~g} \mathrm{(25}$ mmol) of TIPS-based substrate $\mathbf{5} \mathbf{b}$, to provide desired bicyclic product 4 in $95 \%$ yield (Entry 5). Lastly, in order to investigate the mandatory utilization of the Sawamura phosphine 11, a reaction was carried out with a commonly employed phosphine in $\mathrm{Au}(\mathrm{I})$ catalysis, such as JohnPhos (Entry 6). However, a low $10 \%$ conversion was observed. Lengthening the reaction time and/or increasing the temperature did not improve the conversion.

Table 1. 7-exo-dig Cyclization: generation of the catalyst, screening of the substrates and reaction parameters.

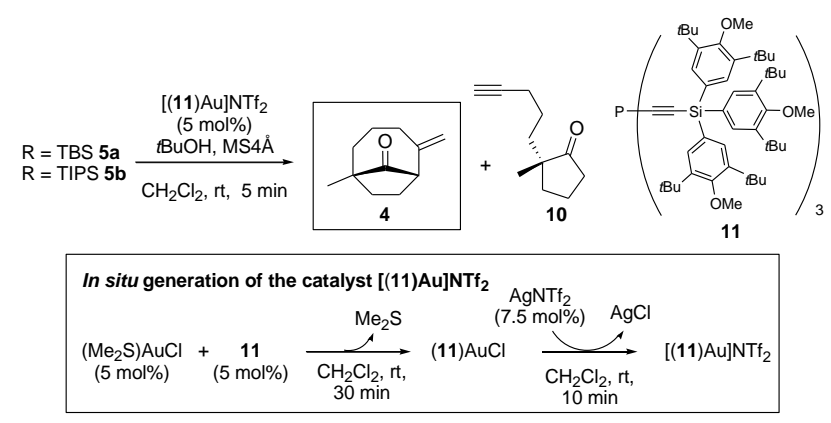

\begin{tabular}{llllll} 
Entry & $\begin{array}{l}\text { Subs- } \\
\text { trate }\end{array}$ & {$[\mathrm{M}]$} & $\begin{array}{l}\text { Conver- } \\
\text { sion }^{\mathrm{a}} \\
(\%)\end{array}$ & $\mathbf{4 / 1 0 ^ { \mathrm { a } }}$ & $\begin{array}{l}\mathbf{4} \text { (Isol. } \\
\text { yield \%) }\end{array}$ \\
1 & $\mathbf{5 a}^{\mathrm{b}}$ & 0.02 & 100 & $8: 92$ & - \\
2 & $\mathbf{5 b}^{\mathrm{b}}$ & 0.02 & 100 & $\geq 95: 5$ & 80 \\
3 & $\mathbf{5 b}^{\mathrm{b}}$ & 0.05 & 100 & $\geq 95: 5$ & 92 \\
4 & $\mathbf{5 b}^{\mathrm{b}}$ & 0.10 & 100 & $\geq 95: 5$ & 95 \\
5 & $\mathbf{5 b}^{\mathrm{c}}$ & 0.6 & 100 & $\geq 95: 5$ & 95 \\
$6^{\mathrm{d}}$ & $\mathbf{5 b}^{\mathrm{b}}$ & 0.05 & 10 & $\geq 95: 5$ & - \\
\hline
\end{tabular}

a: ${ }^{1} \mathrm{H}$ NMR conversion. b: 0.3 mmol. 0 scale. c: 25 mmol. scale. d: JohnPhos was used instead of $\mathbf{1 1 .}$

The functionalization of the bicyclic skeleton 4 constituted the next focus. Several strategies have been studied and we present herein the sequence having allowed the installation of all 
stereocentres in the most straightforward manner, by taking advantage of the cage bicyclic structure of the molecule, as previously mentioned. Ketone $\mathbf{4}$ was stereoselectively reduced to corresponding alcohol in $96 \%$ yield and the hydroxyl group was protected as a benzyl ether 12. This compound readily underwent allylic oxidation promoted by $\mathrm{SeO}_{2}$ and subsequent Dess-Martin oxidation, affording $\alpha, \beta$-unsaturated ketone $\mathbf{1 3}$ in $70 \%$ yield over two steps. The dihydroxylation reaction at the C3-C18 double bond, performed in the presence of a catalytic quantity of potassium osmate dihydrate $\left(\mathrm{K}_{2} \mathrm{OsO}_{4} \cdot 2 \mathrm{H}_{2} \mathrm{O}\right)$, NMO and pyridine, stereoselectively delivered the diol 14 in $90 \%$ yield. ${ }^{12}$ The C3 configuration of $\mathbf{1 4}$ was elucidated by performing NOE NMR experiments. The excellent substrate stereocontrol in these functionalizations validated our hypothesis regarding the stereocontrolled set-up of the stereogenic centres from enantiomerically enriched bicyclo [4.2.1]nonane skeleton of 4. Acetonide $\mathbf{1 5}$ was then readily obtained in $95 \%$ yield from diol 14. The introduction of a phenylselenyl group at $\mathrm{C} 10$ of $\mathbf{1 5}$ and subsequent selenoxide elimination in the presence of $\mathrm{H}_{2} \mathrm{O}_{2}$ and pyridine, produced the desired $\alpha, \beta$ unsaturated ketone 16 in $78 \%$ yield over two steps (Scheme 3). ${ }^{13}$

Scheme 3. Synthesis of the ketones $\mathbf{1 7}$ and $\mathbf{1 8 .}$

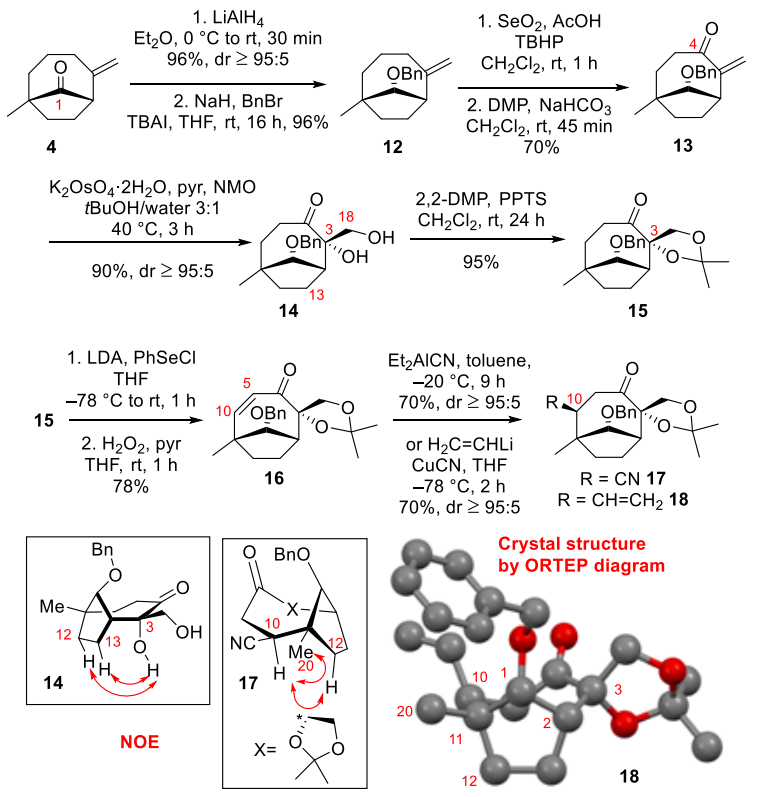

We next focused on the conjugate addition step at C10. Initial attempts to introduce a $\mathrm{MOMOCH}_{2}$ group employing the protocol previously described by Williams in the total synthesis of vibsanin E, proved to be unsuccessful. ${ }^{14}$ The addition of a cyanide anion was foreseen as a good alternative. Thus, $\alpha, \beta$ unsaturated ketone $\mathbf{1 6}$ was treated with 1.1 equiv. of $\mathrm{Et}_{2} \mathrm{AlCN}$ (1M sol. in toluene $)^{15}$ at $-20{ }^{\circ} \mathrm{C}$. Under these conditions, the desired $\gamma$-cyanoketone $\mathbf{1 7}$ was smoothly delivered in $70 \%$ yield as a single diastereomer. The configuration of the newly formed $\mathrm{C} 10$ stereocentre of $\mathbf{1 7}$ was confirmed to be $10(S)$, i.e. the same configuration as the vibsatins, through NOE NMR experiments. In parallel, a vinyl group was introduced by means of a Lipshutz's modified Gilman cuprate. ${ }^{16}$ Practically, a mixture of four equivalents of $\mathrm{CuCN}$ and eight equivalents of vinyllithium ${ }^{17}$ was reacted with 16 at $-78{ }^{\circ} \mathrm{C}$ for $2 \mathrm{~h}$, affording the required $\gamma$-vinylketone $\mathbf{1 8}$ in $70 \%$ yield as a single diastereomer. The configuration of the $\mathrm{C} 10$ centre was established by NOE NMR experiments and the structure was unambiguously confirmed by X-ray crystallography (Scheme 3); interest of such compound was highlighted below. ${ }^{18,19}$

In order to complete the installation of the five stereocentres of the vibsatin skeleton, our attention has been turned to the allylation reaction at the C5 position of ketones $\mathbf{1 7}$ and $\mathbf{1 8}$. This reaction revealed to be much more challenging than expected. Various trials were attempted to perform the reaction on ketones 17 and $\mathbf{1 8}$ and most significant results are presented in Table 2. Noteworthy, only the treatment of $\mathbf{1 7}$ with KHMDS (1.5 equiv.)/DMPU (30 equiv.) and quench with allyliodide, at $-50{ }^{\circ} \mathrm{C}$ for five hours, delivered the desired product 24 albeit in very low yield (15\%), along with unreacted starting material 17 (24\%) and degradation products (Entry 1). Under more drastic conditions, the product 25 featuring the allyl chain at $\mathrm{C} 5$ position but in the opposite configuration was obtained in $30 \%$ yield (Entry 2). Only degradation was observed by treatment of $\mathbf{1 7}$ with NaHMDS (1.2 equiv.)/DMPU (15 equiv.) (Entry 3). Moving towards LiHMDS/DMPU or LDA/HMPA systems led to the compound $\mathbf{2 6}$ with the allyl chain at $\mathrm{C} 10$ in $\alpha$-position to the nitrile group (respectively in 70 and $63 \%$ yields) (Entries 4 and 5). ${ }^{20}$

Table 2. Synthesis of the allylated products 24 and 19: Screening of reaction parameters.

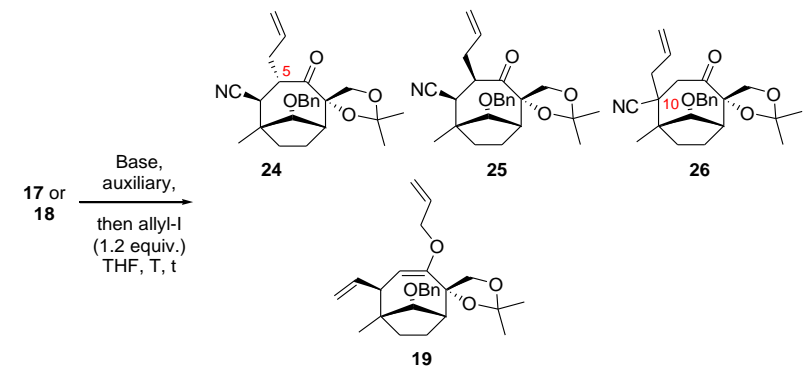

\begin{tabular}{|c|c|c|c|c|}
\hline $\begin{array}{l}\text { En- } \\
\text { try }\end{array}$ & $\begin{array}{l}\text { Subs- } \\
\text { trate }\end{array}$ & $\begin{array}{l}\text { Base (equiv.)/ } \\
\text { Auxiliary } \\
\text { (equiv.) }\end{array}$ & $\mathrm{T}\left({ }^{\circ} \mathrm{C}\right) / \mathrm{t}(\mathrm{h})$ & $\begin{array}{l}\text { Conversion } \\
(\%) / \text { iso- } \\
\text { lated yields } \\
(\%)\end{array}$ \\
\hline $1^{\mathrm{a}}$ & 17 & $\begin{array}{l}\text { KHMDS } \\
(1.5) / \mathrm{DMPU} \\
(30)\end{array}$ & $-50 / 5$ & $\begin{array}{l}76 / 24(15)+ \\
\text { degradation }\end{array}$ \\
\hline $2^{b}$ & 17 & $\begin{array}{l}\text { KHMDS } \\
\text { (5)/DMPU (30) }\end{array}$ & $\begin{array}{l}-78 \text { to } \mathrm{rt} \\
/ 48\end{array}$ & $\begin{array}{l}100 / 25(30) \\
+ \text { degrada- } \\
\text { tion }\end{array}$ \\
\hline 3 & 17 & $\begin{array}{l}\text { NaHMDS } \\
(1.2) / \mathrm{DMPU} \\
(15)\end{array}$ & $-50 / 2.5$ & degradation \\
\hline 4 & 17 & $\begin{array}{l}\text { LiHMDS } \\
(1.2) / \mathrm{DMPU} \\
(30)\end{array}$ & $-50 / 2$ & $100 / 26(70)$ \\
\hline 5 & 17 & $\begin{array}{l}\text { LDA } \\
(1.2) / H M P A(4)\end{array}$ & $-78 / 1.5$ & $100 / 26(63)$ \\
\hline 6 & 18 & $\begin{array}{l}\text { LiHMDS } \\
(1.2) / \mathrm{DMPU} \\
(30)\end{array}$ & $\begin{array}{l}-78 \text { to } \mathrm{rt} \\
/ 24\end{array}$ & $0 /-$ \\
\hline 7 & 18 & $\begin{array}{l}\text { NaHMDS } \\
(1.2) / \mathrm{DMPU} \\
(30)\end{array}$ & $\begin{array}{l}-78 \text { to } \mathrm{rt} \\
/ 24\end{array}$ & $0 /-$ \\
\hline
\end{tabular}


a: allyl-I ( 1.5 equiv.) b: [allyl-Br (7 equiv.), TBAI (0.5 equiv.)] instead of allyl-I (1.2 equiv.).

To circumvent these results, we considered vinyl ketone $\mathbf{1 8}$ as starting material. ${ }^{21}$ Surprisingly, no conversion was observed in the presence of LiHMDS or NaHMDS/DMPU and allyliodide (Entries 6 and 7). Fortunately, by treatment of $\mathbf{1 8}$ with LDA/HMPA and allyliodide, the O-allyl enolate 19 was isolated in $53 \%$ yield (70\% conversion) (Entry 8). ${ }^{22}$ Subsequent microwave-assisted Claisen rearrangement in toluene at 190 ${ }^{\circ} \mathrm{C}$ stereoselectively afforded the desired $C$-allylated product 20 in $89 \%$ yield. ${ }^{23}$ Noteworthy, this procedure set the presumably most favorable trans-relationship between the vinyl and allyl groups. Then, a Wacker oxidation under optimized conditions allowed the formation of the methyl ketone $\mathbf{2 1}$ in $80 \%$ yield along with aldehyde $22(8 \%) .{ }^{14,24}$ The configuration at the C5 stereocentre of both compounds $\mathbf{2 0}$ and $\mathbf{2 1}$ was validated by NOE NMR experiments. Furthermore, the structure of 21 was confirmed by X-ray crystallography which proves the configuration of all stereocentres. ${ }^{25}$ Finally, hydrolysis of the acetonide group in acidic medium led to diol $\mathbf{2 3}$ in $89 \%$ yield (Scheme 4). ${ }^{26}$

Scheme 4. Synthesis of the diol 23.

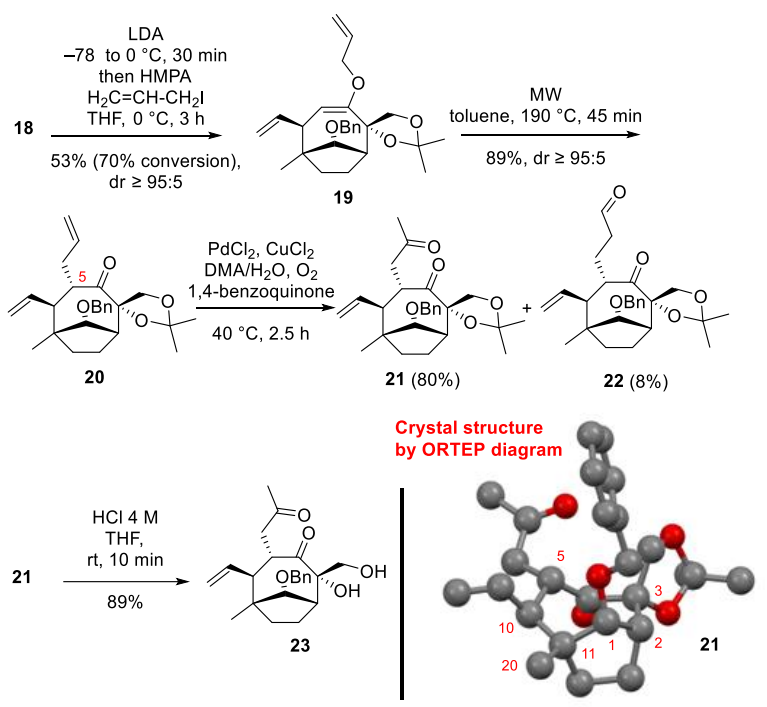

In conclusion, we have developed an efficient method for the asymmetric construction of the bicyclo[4.2.1]nonane core of vibsatin A 1, a new neurotrophic vibsane-type. Thus, a Coniaene derived 7-exo-dig cyclization catalysed by a gold(I) complex permitted the generation of the [5-7]-bicyclic bridged backbone, from an enantiomerically enriched TIPS-based silyl enol ether. The reaction was performed on large scale and constraints formerly associated to glovebox techniques were suppressed. Furthermore, the shape of this framework authorized the installation of all the stereogenic centres without requiring any chiral reagents.

\section{ASSOCIATED CONTENT}

\section{Supporting Information}

The Supporting Information is available free of charge on the ACS Publications website.

Experimental details as well as compound characterization data and copies of ${ }^{1} \mathrm{H}$ and ${ }^{13} \mathrm{C}\{1 \mathrm{H}\}$ NMR spectra are available in the Supporting Information.

\section{Accession Codes}

\section{AUTHOR INFORMATION}

\section{Corresponding Author}

* E-mail: marie-isabelle.lannou@parisdescartes.fr.

* E-mail: geoffroy.sorin@ parisdescartes.fr.

* E-mail: janick.ardisson@ parisdescartes.fr.

\section{Author Contributions}

The manuscript was written through contributions of all authors. All authors have given approval to the final version of the manuscript.

${ }^{\dagger}$ Luca Allievi and Sabrina Dhambri contributed equally.

\section{ORCID}

Luca Allievi: https://orcid.org/0000-0001-7229-1087

Sabrina Dhambri: https://orcid.org/0000-0002-4742-7787.

Marie-Isabelle Lannou: https://orcid.org/0000-0002-3042-2058.

Geoffroy Sorin: https://orcid.org/0000-0001-9656-0771.

Janick Ardisson: https://orcid.org/0000-0001-5009-1527.

Notes

The authors declare no competing financial interest.

\section{ACKNOWLEDGMENT}

Universite de Paris is acknowledged for a Ph. D. fellowship to Dr. L. Allievi. The authors gratefully thank Dr. C. Meyer (ESPCI, ParisTech, Paris), Dr. C. Pichon and Dr. S. Sengmany (ICMPE, UPEC) for technical support. We would like to thank Dr. R. Guillot from single-crystal X-ray diffraction service ICMMO-UMR 8182 Orsay.

\section{REFERENCES}

(1) Woodward, R. B. Neuere Entwicklungen in der Chemie der Naturstoffe. Angew. Chem. 1956, 68, 13-20.

(2) Lim, K.-H.; Hiraku, O.; Komiyama, K.; Koyano, T.; Hayashi, M.; Kam, T.-S. Biologically active indole alkaloids from Kopsia arborea. J. Nat. Prod. 2007, 70, 1302-1307.

(3) Dong, M.; Cong, B.; Yu, S.-H.; Sauriol, F.; Huo, C.-H.; Shi, Q.-W.; Gu, Y.-C.; Zamir, L. O.; Kiyota, H. Echinopines A and B: Sesquiterpenoids Possessing an Unprecedented Skeleton from Echinops spinosus. Org. Lett. 2008, 10, 701-704.

(4) Gao, X.; Shao, L.-D.; Dong, L.-B.; Cheng, X.; Wu, X.-D.; Liu, F.; Jiang, W.-W.; Peng, L.-Y.; He, J.; Zhao, Q.-S. Vibsatins A and B, Two New Tetranorvibsane-Type Diterpenoids from Viburnum tinus cv. variegatus. Org. Lett. 2014, 16, 980-983.

(5) (a) Xu, J.; Lacoske, M. H.; Theodorakis, E. A. Neurotrophic Natural Products: Chemistry and Biology. Angew. Chem. Int. Ed. 2014, 53, 956-987. (b) Josephy-Hernandez, S.; Jmaeff, S.; Pirvulescu, I.; Aboulkassima, T.; Saragovi, H. U. Neurotrophin receptor agonists and antagonists as therapeutic agents: An evolving paradigm. Neurobiol. Dis. 2017, 97, 139-155.

(6) (a) Kubo, M.; Esumi, T.; Imagawa, H.; Fukuyama, Y. Chemical Diversity of Vibsane-Type Diterpenoids and Neurotrophic Activity and Synthesis of Neovibsanin. Studies in Natural Products Chemistry 2014, 43, 41-78. (b) Mak, J. Y. W.; Williams C. M. Key Achievements in the Total Synthesis of Vibsane-type Diterpenoids. Nat. Prod. Rep. 2012, 29, 440-448.

(7) (a) Conia, J. M.; Le Perchec, P. The Thermal Cyclization of Unsaturated Carbonyl Compounds. Synthesis 1975, 1-19. (b) Hack, D.; Blumel, M.; Chauhan, P.; Philipps, A. R.; Enders, D. Catalytic Conia-ene and Related Reactions. Chem. Soc. Rev. 2015, 44, 60596093. (c) Lina, E.-Z.; Xub, Y.; Jia, K.; Ye, L.-W. Recent Advances towards Catalytic Asymmetric Conia-ene-type Reactions. Chin. 
Chem. Lett. 2021, 32, 954-962. (d) Huang, E.-H.; Zhang, Z.-X.; Ye, S.-H.; Chen, Y.-B.; Luo, W.-F.; Qian, P.-C.; Ye, L.-W. CopperCatalyzed Carbocyclization of Silyl Enol Ether Tethered Ynamides for Efficient and Practical Synthesis of 2-Azabicyclo[3.2.0] Compounds. Chin. J. Chem. 2020, 38, 1086-1090. (e) Carrër, A.; Péan, C.; Perron-Sierra, F.; Mirguet, O.; Michelet, V. Gold-Catalyzed Cyclizations of Alkynyl Silyl Enol Ethers: An Easy Access to Bicyclo[3.2.1] octanone Derivatives. Adv. Synth. Catal. 2016, 358, 15401545. (f) Cao, M.; Yesilcimen, A.; Wasa, M. Enantioselective ConiaEne-Type Cyclizations of Alkynyl Ketones through Cooperative Action of $\mathrm{B}\left(\mathrm{C}_{6} \mathrm{~F}_{5}\right)_{3}, \mathrm{~N}-$ Alkylamine and a $\mathrm{Zn}$-Based Catalyst. $J$. Am. Chem. Soc. 2019, 141, 4199-4203.

(8) (a) Ito, H.; Ohmiya, H.; Sawamura, M. Construction of Methylenecycloheptane Frameworks through 7-Exo-Dig Cyclization of Acetylenic Silyl Enol Ethers Catalyzed by TriethynylphosphineGold Complex. Org. Lett. 2010, 12, 4380-4383. For other works, see: (b) Ochida, A.; Ito, H.; Sawamura, M. Using Triethynylphosphine Ligands Bearing Bulky End Caps To Create a Holey Catalytic Environment: Application to Gold(I)-Catalyzed Alkyne Cyclizations. J. Am. Chem. Soc. 2006, 128, 16486-16487. (c) Ochida, A.; Sawamura, M. Phosphorus Ligands with a Large Cavity: Synthesis of Triethynylphosphines with Bulky End Caps and Application to the Rhodium-Catalyzed Hydrosilylation of Ketones. Chem. Asian J. 2007, 2, 609-618. (d) Iwai, T.; Okochi, H.; Ito, H.; Sawamura, M. Construction of Eight-Membered Carbocycles through Gold Catalysis with Acetylene-Tethered Silyl Enol Ethers. Angew. Chem. Int. Ed. 2013, 52, 4239-4242.

(9) (a) Pfau, M.; Revial, G.; Guingant, A.; d'Angelo, J. Enantioselective Synthesis of Quaternary Carbon Centers through MichaelType Alkylation of Chiral Imines. J. Am. Chem. Soc. 1985, 107, 273274. (b) d'Angelo, J.; Desmaële, D. A New Strategy for the Enantioselective Synthesis of Aspidosperma Alkaloids: I - Construction of the [ABC]-Type Tricyclic Intermediates. Tetrahedron Lett. 1990, 31, 879-882. (c) d'Angelo, J.; Desmaële, D.; Dumas, F.; Guingant, A. The Asymmetric Michael Addition Reactions Using Chiral Imines. Tetrahedron: Asymmetry 1992, 3, 459-505.

(10) Morisson, V.; Bamier, J. P.; Blanco, L. Enzymatic Resolution of Bicyclo[n.1.0]alkan-1-ols Derivatives: Preparation of Optically Active $\alpha$-Substituted $\alpha$-Methylcycloalkanones. Tetrahedron 1998 $54,7749-7764$.

(11) Schäfer, C.; Miesch, M.; Miesch, L. Intramolecular Reductive Ketone-Alkynoate Coupling Reaction Promoted by $\left(\eta^{2}-\right.$ Propene)Titanium. Org. Biomol. Chem. 2012, 10, 3253-3257.

(12) Martín Hernando, J. I.; Rico Ferreira, M. d. R.; Candela Lena, J.I.; Birlirakis, N.; Arseniyadis, S. Studies towards the Taxoid Diterpene ABC-Ring System: Practical Access to Highly Functionalized Enantiomerically Pure Analogues of Major Group Representatives. Tetrahedron: Asymmetry 2000, 11, 951-973.

(13) In order to install the $\alpha, \beta$-unsaturation, various methods were examined before the utilization of $\mathrm{PhSeCl}$, but have proved to be ineffective. (a) Nicolaou, K. C.; Montagnon, T.; Baran P. S. Modulation of the Reactivity Profile of IBX by Ligand Complexation: Ambient Temperature Dehydrogenation of Aldehydes and Ketones to $\alpha, \beta$ Unsaturated Carbonyl Compounds. Angew. Chem. Int. Ed. 2002, 41, 993-996. (b) Nicolaou, K. C.; Gray, D. L. F.; Montagnon, T.; Harrison S. T. Oxidation of Silyl Enol Ethers by Using IBX and IBX.NOxide Complexes: a Mild and Selective Reaction for the Synthesis of Enones. Angew. Chem. Int. Ed. 2002, 41, 996-1000. (c) Tsuji, J.; Minami, I.; Shimizu, I. A Novel Palladium-Catalyzed Preparative Method of $\alpha, \beta$-Unsaturated Ketones and Aldehydes from Saturated
Ketones and Aldehydes via their Silyl Enol Ethers. Tetrahedron Lett. 1983, 24, 5635-5638. (d) Larock, R. C.; Hightower, T. R.; Kraus, G. A.; Hahn, P.; Zheng, D. A Simple, Effective, New, PalladiumCatalyzed Conversion of Enol Silanes to Enones and Enals. Tetrahedron Lett. 1995, 36, 2423-2426. (e) Ohshima, T.; Xu, Y.; Takita, R.; Shimizu, S.; Zhong, D.; Shibasaki, M. Enantioselective Total Synthesis of (-)-Strychnine Using the Catalytic Asymmetric Michael Reaction and Tandem Cyclization. J. Am. Chem. Soc. 2002, 124, 1454614547.

(14) Schwartz B. D.; Denton J. R.; Lian Y.; Davies H. M. L.; Williams C. M. Asymmetric [4+3] Cycloadditions between Vinylcarbenoids and Dienes: Application to the Total Synthesis of the Natural Product (-)-5-epi-Vibsanin E. J. Am. Chem. Soc. 2009, 131, 8329-8332.

(15) Tanaka, R.; Ohishi, K.; Takanashi, N.; Nagano, T.; Suizu, H.; Suzuki, T.; Kobayashi, S. Synthetic Study of Pyrrocidines: First Entry to the Decahydrofluorene Core of Pyrrocidines. Org. Lett. 2012, $14,4886-4889$.

(16) Lipshutz, B. H.; Sharma, S.; Ellsworth, E. L. "Higher Order" Cyanocuprates $\mathrm{R}_{2} \mathrm{Cu}(\mathrm{CN}) \mathrm{Li}_{2}$ : Discrete Reagents or "Lower Order" LiCN-Modified Gilman Cuprates? J. Am. Chem. Soc. 1990, $112,4032-4034$.

(17) For the preparation of vinyllithium, see: Chapman, L. M.; Beck, J. C.; Wu, L.; Reisman, S. E. Enantioselective Total Synthesis of (+)-Psiguadial B. J. Am. Chem. Soc. 2016, 138, 9803-9806.

(18) Crystallographic data of compound $\mathbf{1 8}$ are available from the Cambridge Crystallographic Data Centre: reference CCDC no. 2081038.

(19) As anticipated, the dihydroxylation reaction took place on the endo face due to the steric hindrance of the exo face of olefin $\mathbf{1 3}$ by the benzyl ether. The subsequent 1,4-addition occurred on the exo face, presumably owing to the specific conformation of the enone $\mathbf{1 6}$.

(20) The C10 configuration of compound 26 could not be confirmed by NOE NMR experiments.

(21) Enolate allylation directly following Gilman vinylcuprate addition was initially attempted, but mainly led to decomposition.

(22) Schwartz, B. D.; Denton, J. R.; Bernhardt P. V.; Davies, H. M. L; Williams, C. M. Towards the Total Synthesis of 3Hydroxyvibsanin E. Synthesis 2009, 17, 2840-2846.

(23) Schwartz, B. D.; Williams, C. M.; Bernhardt, P. V. End Game Strategies towards the Total Synthesis of Vibsanin E, 3Hydroxyvibsanin E, Furanovibsanin A, and 3-OMethylfuranovibsanin. Beilstein J. Org. Chem. 2008, 4, No. 34.

(24) (a) Hennig, R.; Metz, P. Enantioselective Synthesis of 4Desmethyl-3 $\alpha$-Hydroxy-15-Rippertene. Angew. Chem. Int. Ed. 2009, 48, 1157-1159. (b) Derdar, F.; Martin, J.; Martin, C.; Brégeault, J.M.; Mercier, J. Cétonisation catalytique du méthyl-2-butène-3-ol-2 par des complexes du rhodium(III) ou du palladium(II). J. Organomet. Chem. 1988, 338, C21-C26. (c) Zaghouani, M.; Gayraud, O.; Jactel, V.; Prévost, S.; Dezaire, A.; Sabbah, M.; Escargueil, A.; Lai, T.-L.; Le Clainche, C.; Rocques, N.; Romero, S.; Gautreau, A.; Blanchard, F.; Frison, G.; Nay, B. Multifaceted Study on a Cytochalasin Scaffold: Lessons on Reactivity, Multidentate Catalysis and Anticancer Properties. Chem. Eur. J. 2018, 24, 16686-16691.

(25) Crystallographic data of compound $\mathbf{2 1}$ are available from the Cambridge Crystallographic Data Centre: reference CCDC no. 2081039.

(26) Investigations towards the total synthesis of vibsatin A are currently in progress. 